\title{
Attitudes of Primary School Students in Saudi Arabia Towards Using PowerPoint Program in Classroom
}

\author{
Mohammed Elmetwali Mohammed Amer ${ }^{1}$ \\ ${ }^{1}$ Computer Science and Information Department, College of Science and Humanity Studies, Prince Sattam bin \\ Abdulaziz University, Al-Sulail, Saudi Arabia \\ Correspondence: Mohammed Elmetwali Mohammed Amer, Assistant Professor, Computer Science and \\ Information Department, College of Science and Humanity Studies, Prince Sattam bin Abdulaziz University, \\ Al-Sulail, Saudi Arabia.
}

Received: July 31, 2020

Accepted: September 1, 2020

Online Published: September 4, 2020

doi:10.20849/aes.v5i2.794

URL: https://doi.org/10.20849/aes.v5i2.794

\begin{abstract}
The present study aimed to explore the attitudes of primary school students in Saudi Arabia towards using PowerPoint program in classroom. A descriptive analytical approach was adopted and a questionnaire was developed. The researcher selected a purposive sample consisting of 305 sixth grade male students from five primary schools in Al-Sulail, Saudi Arabia. The questionnaire forms were distributed to all of those students. All of the distributed forms were retrieved and considered valid for analysis. SPSS program was used. It was found that most of the primary school students in Saudi Arabia have excellent skills in using the PowerPoint program. It was found that primary school students in Saudi Arabia have positive attitudes towards using PowerPoint program in classroom. It was found that using PowerPoint enriches students' knowledge, and increases their concentration, and academic achievement. It was found that using PowerPoint improves students' understanding of the material, problem solving skills, and information retention.
\end{abstract}

Keywords: attitudes, powerpoint, primary school students, Saudi Arabia

\section{Introduction}

Today, computer plays a very significant role. For instance, it enables people and nations to develop, advance and obtain knowledge. Therefore, the use of computer has been increasing much in all the fields, including the educational field. For instance, today, almost all of the lecture halls in universities and classrooms in schools include a computer and a data show device. That's because computer is considered as an effective mean for teaching and learning. For instance, using computer in education enables students to learn fast and enables teachers to speed up the teaching process. It enables students to acquire the complex skills which acquisition requires much time. It offers students many learning opportunities and participates in meeting the students' academic needs. It increases the students' interests in the things they are learning about. It improves the process of training students and enables students to carry out classroom activities that are consistent with their capabilities. It participates in the development of students' skills and capabilities and enables students to learn more concepts. It makes the learning process an easy, fun, and enjoyable process.

There are many merits for using computer in education. For instance, computer doesn't require much cost. In addition, it serves as an appropriate learning method for various categories of students, such as: children, gifted students, and the students with special needs, including the students with learning difficulties. It enables teachers to use a variety of teaching methods effectively. For instance, it enables teachers to employ electronic games in the classroom. It raises the quality of the teaching-learning process (Al-Hashmi et al., 2010).

Computer includes many programs and applications that enrich students' knowledge and develop their skills and expertise (Al-Hashmi et al., 2010). Such programs may include: the PowerPoint program which was developed in 1987 (Gomez, 2007). Using the PowerPoint program in education enriches students' knowledge (Shigli et al., 2016). It increases students' interest in the material and enriches their factual knowledge. It increases students' engagement and participation (Ankolekar et al., 2017). It participates in raising student's academic achievement in courses, including in mathematics (Abed Al-Rahman, 2016), art courses, (Al-Taher, 2016), sport courses (Al-Shamsi, 2018) and engineering courses. It increases students' interaction with one another within the classroom. It enables teachers to save their time and reduce the effort exerted during the teaching process. 
Using PowerPoint program in education enables teachers to meet the goals of the teaching process. It improves students' capability to apply knowledge and retrieve information (Al-Radi, 2016). It serves as an effective mean for teaching students with learning difficulties (Jalal, 2019). In addition, it improves students' drawing and coloring skills and serves as an effective mean for teaching art (Al-Taher, 2016).

PowerPoint program can be used for presenting texts, multimedia, and visual and auditory effects. It enables its user to present a great amount of information and save time when presenting and illustrating information. It facilitates the process of sharing knowledge. That's because it facilitates the process of sending, copying, saving and printing and uploading files. It enables students to identify the main ideas and points of the lesson. That enables students to save time when studying for the exam. Using the PowerPoint program enables teachers and students to use language in a manner that is more accurate when presenting information in class. That's because this program detects to the language mistakes, including the spelling and grammatical mistakes. In addition, this program enables students and instructors to present terms and ideas in a manner that is more organized (Xingeng, and Jianxiang, 2012).

Despite the benefits of PowerPoint, it is very significant to explore the attitudes of students, instructors and trainers towards PowerPoint. That is because students' attitudes towards the instructional mean and computer programs shall affect their academic achievement. Thus, if instructors use a mean or a computer program that students don't life, students' academic achievement shall be negatively affected (Papanastasiou and Zembylas, 2002). Therefore, the researcher of the present study aimed to explore the attitudes of primary school students in Saudi Arabia towards using PowerPoint program in classroom.

\section{The Objectives of the Study}

This study aimed at:

- Assessing the competency of primary school students in Saudi Arabia in using the PowerPoint program.

- Identifying the attitudes of primary school students in Saudi Arabia towards using PowerPoint program in classroom.

\section{The Questions of the Study}

This study aimed at answering those questions:

Q.1. How competent are primary school students in Saudi Arabia in using the PowerPoint program?

Q.2 What are the attitudes of primary school students in Saudi Arabia towards using PowerPoint program in classroom?

\section{Significance of the Study}

The present study is significant due the scarcity of the studies that shed a light on the use of PowerPoint in Saudi primary classrooms. Thus, it participates in filling a gap in the relevant literature. It is considered significant because it's useful for:

a) Primary school students in Saudi Arabia: This study enriches those students' knowledge about the merits of integrating computer programs in the learning process.

b) Teachers in Saudi Arabia: This study enriches those teachers' knowledge about the merits of integrating computer programs in the learning process. In addition, the results of the present study enable those teachers to improve their teaching methods and develop themselves professionally.

c) Officials in the Saudi Ministry of Education: This study shall provide those officials with information about the competency of primary school students in using the PowerPoint program. Such information shall enable those officials to make effective decisions to improve such competency. This study shall promote knowledge among those officials about the merits of integrating technology-including computer programsin the education field. Such knowledge shall encourage those officials to make effective decisions that aim at developing the IT infrastructure of Saudi schools.

d) Researchers: The present study provides researchers with a reliable instrument that can be used to explore students' attitudes towards using PowerPoint program in classroom.

\section{Limits of the Study}

The present study was conducted during the $1^{\text {st }}$ semester of the academic year 2019/2020. It was conducted in five primary schools in Al-Sulail, Saudi Arabia. It targets primary school students in Saudi Arabia. 


\section{Definitions}

\subsection{Theoretical Definitions}

- The PowerPoint program: This program enables its users to present information through using slides. Students and teachers use it to make presentations in classrooms. This programs includes visual, auditory, color, motion and light effects. Such effects attract the attention of students (Al-Shamat et al., 2013; p.283).

- Attitudes: They refer to one's negative or positive feelings about doing a specific behavior (Fishbein and Ajzen 1975, p. 216).

\subsection{Operational Definitions}

The PowerPoint program: It's a program used by primary school teachers in Saudi Arabia for making presentations and illustrating information.

- $\quad$ Attitudes: They refer to the attitudes of primary school students in Saudi Arabia towards using PowerPoint in Program.

\section{Review of Literature}

Al-Rasheedi (2013) aimed to explore the attitudes of the students enrolled at the basic education faculty in Kuwait towards using PowerPoint by their instructors. The random sampling methods was used. The sample consists from 651 students. A questionnaire was used. It was found that PowerPoint enables students to identify the main ideas and points of the lecture and develops students' higher thinking skills. PowerPoint enables instructors to take individual differences between the students into consideration. It enables students to understand concepts, including abstract concepts. It increases the interaction between studentsand their peers and makes the complex materials easier to understand. It makes the processes of learning and revising information enjoyable. It enables instructors to display a greater number of terms during the lecture.

Al-Shamat et al. (2013) aimed to explore the attitudes of $10^{\text {th }}$ grade students in Damascus towards using PowerPoint in geography course. They aimed to explore the impact of PowerPoint on academic achievement. An experimental approach and analytical descriptive approaches were adopted. A pre-test, and a post-test were administered and a questionnaire was used. The sample consists from 180 students. Those students were selected from two $10^{\text {th }}$ grade sections. It was found that respondents have positive attitudes towards using PowerPoint in geography course. PowerPoint increases students' academic achievement and interest in the course. It enables students to acquire skills and offers them flexible and convenient learning opportunities. It enables students to understand the material and enables teachers to meet the curriculum goals and dedicate more time for teaching students. It enables students to retain information for a longer time and improves the student-instructor interaction. It motivates students to learn and facilitates the process of assessing students.

Ali and Sbeira (2014) aimed to explore the attitudes of the students enrolled in applied sciences faculties in Tishreen University towards using the data show device during the lecture. They aimed to explore the impact of using this device on students' motivation to learn. The sample consists from 491 female and male students. A questionnaire was used and means and standard deviations were calculated. Analysis of variance and Sheffeh test were conducted. It was found that using the data show device motivates students to learn. The respondents have positive attitudes towards using this device. Using this device doesn't improve students' understanding for the material. It enables instructors to offer more examples and carry out activities during the lecture. It attracts students' attention and enables instructors to meet the academic goals of the lecture (Ali and Sbeira, 2014).

Using the data show device increases students' concentration levels and promotes positive competitiveness. It offers more opportunities for discussion and improves the student-instructor interaction. It enables the instructor to display questions that encourage students to think more. It can be used in any course. It enables the instructor to deliver the intended information. It increases students' trust in his/her academic potentials and desire to attend the lectures delivered by the instructor who uses this device (Ali and Sbeira, 2014).

Al-Shayeb and Ayesh (2014) aimed to explore the attitudes of university students towards using PowerPoint in the lecture. They aimed to explore the impacts of using PowerPoint on motivation, interaction and academic achievement. The sample consists from 111 students who were selected from the University of Ouergla in Algeria. A sixteen-item questionnaire was used. Percentages, and frequencies were calculated and the t-test was conducted. It was found that the PowerPoint plays an effective role in raising students' motivation to learn and academic achievement and improving the interaction between the instructor and the students. PowerPoint facilitates the process of understanding the material and makes the lecture enjoyable and less complicated. It attracts students' attention and increases their concentration. 
Mohsenzadeh et al. (2014) aimed to explore the attitudes of EFL undergraduates and their instructors towards using PowerPoint during the lecture in Iran. The sample consists from 50 undergraduates and 10 instructors. It was selected from Islamic Azad University, and Payam Noor University in Shadegan, Iran. A questionnaire was developed for instructors and another questionnaire was developed for students. It was found that teachers and instructors have positive attitudes. It was found that the instructors' believe that PowerPoint saves the wasted times writing on board, and wasted costs and improves time management and classroom management skills. Instructors believe that this program facilitates the process of summarizing, revising and illustrating information. They add that this program increases the time dedicated for teaching. They add that this program enables them to display the material and information sources in font of all the students. As for students, they believe that this program makes learning enjoyable, improves their concentration and motivates them to learn. They add that this program increases their participation and engagement in the learning process and improves the way they interact with each other (Mohsenzadeh et al., 2014).

Lari (2014) aimed to explore the effectiveness of using PowerPoint in teaching secondary school students in Iran and improving their motivation to learn. The sample consists from 56 students. A pre-test, and a post-test were administered and a questionnaire was used. It was found that using PowerPoint improves students' motivation to learn. PowerPoint increases students' interest in the course and understanding of the information. It improves students' note taking skills and raises their concentration. It was found that using PowerPoint enables students to identify the main points and ideas of the lecture.

Ahmad (2016) aimed to explore the effectiveness of using PowerPoint in teaching students in electricity course in avocational training center in Sudan. The purposive sampling method was used. The sample consists from 30 students. A pre-test, and a post-test were administered and the observation method was used. For instance, instructors were observed during the lesson. Interviews were conducted. For instance, the researcher interviewed the head of the electricity department in the selected vocational training center in Karay, Sudan. SPSS was used. It was found that PowerPoint increases students' academic achievement in the electricity course. PowerPoint increases students' concentration and interest in the courseand attracts students' attention. It offers discussion opportunities and increases students' academic engagement and participation. It encourages students to explore things, ask questions and raises their self-confidence levels. It raises students' desire to obtain knowledge and learn. It increases students' understanding for the material and engagement in the teaching-learning process.

Liu et al. (2016) aimed to explore teachers' attitudes towards using PowerPoint in kindergartens in China. 62 kindergarten teachers were sampled and data was collected from them through using a questionnaire. It was found that kindergartens in China provide the needed equipment for using PowerPoint in classroom. It was found that teachers frequently use PowerPoint at classroom. It was found that using PowerPoint boosts children's development in emotional, social and cognitive areas.

Ahmad (2017) aimed to explore the effectiveness of using PowerPoint in teaching biology in Sudan. He aimed to explore the effectiveness of using PowerPoint in raising students' academic achievement. A pre-test, and a post-test were administered and a questionnaire was used. An experimental approach was adopted. An analytical descriptive approach was adopted. The sample consists from 60 students who were selected from MartyrFathi Hemat Secondary School for Boys in Dongola. Those students were divided equally into experimental and control groups. It was found that using the PowerPoint plays an effective people in raising students' academic achievement in biology course. It was found that using PowerPoint attracts students' attention in the biology course.

Salman (2018) aimed to explore the attitudes of university students in Iraq towards using PowerPoint in lectures in Iraq. A questionnaire was used. The sample consists from 68 female and male students who were selected from the faculty of education in Baghdad University. It was found that using PowerPoint improves students reading skills and enables them to identify the main points of the lecture and take notes efficiently. It was found that using the PowerPoint improves students' understanding of information and attracts their attention, because this program includes motion and color effects. It was found that using PowerPoint makes students active participants in the lecture and motivates them to learn.

Al-Shamsi (2018) aimed to explore the impact of using PowerPoint in classroom on students' academic achievement in physical education course in Al-Buraimi, Oman. An experimental approach was adopted. A pre-test, and a post-test were administered and an observation card was used. The sample consists from 40 students. Those students were selected from a public school called (Azan bin Qais for Primary Education). They were divided into experimental and control groups. It was found that using PowerPoint plays an effective role in raising students' academic achievement in physical education course. It was found that using PowerPoint plays 
an effective role in raising students' physical education-related knowledge and skills.

\section{Methodology}

8.1 Approach

A descriptive analytical approach was adopted.

\subsection{Data Collection Methods}

The researcher used a questionnaire and reviewed the relevant theses, books and studies.

\subsection{Methods of Data Analysis}

To analyze data, SPSS program was used. The researcher calculated standard deviations and means. That is done to explore the attitudes of primary school students in Saudi Arabia towards using PowerPoint program in classroom. The researcher calculated percentages and frequencies. That is done to assess the competency of primary school students in Saudi Arabia in using the PowerPoint program. The researcher calculated the value of Cronbach Alpha coefficient to measure the questionnaire's reliability.

\subsection{Methods for Classifying Means}

For classifying the means, the researcher adopted the criteria displayed below in in Table 1 .

Table 1. The criteria adopted for the classification of means

\begin{tabular}{ccc}
\hline Range & Level & Attitude \\
\hline 2.33 or less & Low & Negative attitude \\
\hline $2.34-3.66$ & Moderate & Neutral attitude \\
\hline 3.67 or more & High & Positive attitude
\end{tabular}

*Source: Al-Amery (2020)

\subsection{Population and Sample}

The population involves all the primary school students in Saudi Arabia. The researcher selected a purposive sample consisting of 305 sixth grade male students from five primary schools in Al-Sulail, Saudi Arabia. The questionnaire forms were distributed to all of those students. All of the distributed forms were retrieved and considered valid for analysis. The response rate is $100 \%$.

\subsection{Instrument}

The researcher developed a questionnaire consisting from two parts. The 5-point Likert questionnaire was adopted. The first part of the questionnaire aims at collecting data about the competency of primary school students in Saudi Arabia in using the PowerPoint program. The second part aims at collecting data about the respondents' attitudes. It was developed based on the studies of Al-Shamsi (2018),Jalal (2019), Ahmad (2017), Lari (2014), Mohsenzadeh et al. (2014),Ali and Sbeira (2014), Salman (2018), Xingeng, and Jianxiang (2012), Ul-Amin (2016), Al-Shayeb and Ayesh (2014), Al-Hashmi et al. (2010), Al-Rasheedi (2013), and Neira et al. (2013). Through the cover page of the questionnaire, the researcher confirmed that the collected data shall remain confidential.

\subsection{Validity}

To check the instrument's validity, the preliminary version of the questionnaire was sent to 2 experts. Those experts are specialized in educational fields and work at a Saudi university. The researcher requested those experts to assess the questionnaire in terms of language, relevancy, and clarity of items. He requested them to make the necessary adjustments and provide suggestions. Those experts suggested that the instrument's language is clear and correct. They suggested that the instrument is relevant and capable of meeting the goals of this study. However, one of the experts recommended deleting a statement and the other expert made changes to the form of the questionnaire. In the light of that, changes were made to produce the final version of the questionnaire.

\subsection{Reliability}

The researcher calculated the value of Cronbach Alpha coefficient to measure the questionnaire's reliability. The latter value is 0.898 which is considered high. It was calculated through using the SPSS program. It indicates that the instrument is very reliable. 


\section{Results and Discussion}

\subsection{Results and Discussion Related to the First Question}

Percentages and frequencies were calculated about the respondents' competency in using the PowerPoint program. These values are presented in Table 2 below.

Table 2. The respondents' competency in using the PowerPoint program

\begin{tabular}{cccc}
\hline Question & Category & Frequency & Percentage\% \\
\hline How do you assess your & Excellent & 153 & 50.16 \\
\cline { 2 - 4 } $\begin{array}{c}\text { competency in using the } \\
\text { PowerPoint program? }\end{array}$ & very good & 52 & 17.04 \\
\cline { 2 - 4 } & Good & 56 & 18.36 \\
\cline { 2 - 4 } & Fair & 27 & 8.85 \\
& Poor & 17 & 5.57 \\
\hline
\end{tabular}

Based on Table 2, it was found that $50.16 \%$ of the respondents have excellent skills in using the PowerPoint program, and $17.04 \%$ of the respondents have very good skills in using the PowerPoint program. It was found that $18.36 \%$ of the respondents have good skills in using this program, and $8.85 \%$ of the respondents have fair skills in in using this program. It was found that $5.57 \%$ of the respondents have poor skills in using this program. That indicates that most of the primary school students in Saudi Arabia have excellent skills in using the PowerPoint program. That indicates that students in Saudi Arabia are provided with education of high quality in the IT field.

\subsection{Results and Discussion Related to the Second Question}

Q.2 What are the attitudes of primary school students in Saudi Arabia towards using PowerPoint program in classroom?

To answer the second question, means and standard deviations are calculated. These values are displayed through Table 3 below:

Table 3. The means and standard deviations for identifying the students' attitudes towards using PowerPoint Program in classroom

\begin{tabular}{llllll}
\hline No. & Statement & Mean & Std. & Level & Attitude \\
\hline Using PowerPoint in classroom: & & & & \\
\hline 1 & enriches my knowledge & 4.96 & 0.65 & High & Positive \\
\hline 2 & increases my interest in the course and the material & 2.22 & 0.67 & Low & Negative \\
\hline 3 & increases my concentration during the class & 4.81 & 0.51 & High & Positive \\
\hline 4 & $\begin{array}{l}\text { improves the teachers' capabilities to manage and utilize time } \\
\text { effectively }\end{array}$ & 2.12 & 0.34 & Low & Negative \\
\hline 5 & increases my academic achievement & 4.73 & 0.77 & High & Positive \\
\hline 6 & increases my desire to attend class & 2.30 & 0.86 & Low & Negative \\
\hline 7 & facilitates the process of understanding the material & 4.67 & 0.60 & High & Positive \\
\hline 8 & improves students' problem solving skills & 4.59 & 0.95 & High & Positive \\
\hline 9 & increases the students-teacher interaction during class & 2.24 & 0.11 & Low & Negative \\
\hline 10 & facilitates the process of sharing knowledge & 4.85 & 0.58 & High & Positive \\
\hline 11 & enables me to retain information for a longer time & 4.73 & 0.08 & High & Positive \\
\hline 12 & creates a classroom environment that is free from the feelings of & 2.19 & 0.66 & Low & Negative \\
& anxiety and shyness which are associated with learning & & & & \\
\hline & & & &
\end{tabular}




\begin{tabular}{llllll}
\hline 13 & enables me to identify the main ideas and points of the lesson & 4.69 & 0.73 & High & Positive \\
\hline 14 & improves my creative thinking capabilities & 4.91 & 0.59 & High & Positive \\
\hline 15 & improves my higher order thinking capabilities & 4.82 & 0.43 & High & Positive \\
\hline 16 & is considered an effective teaching method in all the courses & 2.09 & 0.56 & Low & Negative \\
\hline & Total & 3.80 & 0.56 & High & Positive \\
\hline
\end{tabular}

Based on the third table, it was found that primary school students in Saudi Arabia have positive attitudes towards using PowerPoint Program in classroom. That is because the overall mean is 3.80 . Using PowerPoint enriches students' knowledge, because the relevant mean is 4.94. The latter result is consistent with the result concluded by Al-Shamsi (2018). Using PowerPoint doesn't increase students' interest in the course and the material, because the relevant mean is 2.22.The latter result is inconsistent with the result concluded by Ahmad (2016). Using PowerPoint increases students' concentration during the class, because the relevant mean is 4.81 . The latter result is consistent with the result concluded by Lari (2014).

Using PowerPoint doesn't improve the teachers' capabilities to manage and utilize time effectively, because the relevant mean is 2.12. The latter result is inconsistent with the result concluded by Mohsenzadeh et al. (2014). Using PowerPoint increases students' academic achievement because the relevant mean is 4.73 . The latter result is consistent with the result concluded by Ahmad (2017). Using PowerPoint doesn't increase students' desire to attend class because the relevant mean is 2.30 . The latter result is inconsistent with the result concluded by Ali and Sbeira (2014). That may be attributed to the fact that students' desire to attended class is affected by the teacher's personality, skills and capabilities to present the material in an interesting manner.

Using PowerPoint facilitates the process of understanding the material, because the relevant mean is 4.67. The latter result is consistent with the result concluded by Salman (2018). Using PowerPoint improves students' problem solving skills, because the relevant mean is 4.59. The latter result is consistent with the result concluded by Ul-Amin (2016). Using PowerPoint doesn't increase the students-teacher interaction during class, because the relevant mean is 2.24. The latter result is inconsistent with the result concluded by Al-Shayeb and Ayesh (2014). The latter result may be attributed to the fact that such interaction is affected by the teacher's personality, social skills and desire to interact with students. Using PowerPoint facilitates the process of sharing knowledge, because the relevant mean is 4.85 . The latter result is consistent with the result concluded by Xingeng, and Jianxiang (2012).

Using PowerPoint enables students to retain information for a longer period of time, because the relevant mean is 4.73. The latter result is consistent with the result concluded by Al-Hashmi et al. (2010). The latter result may be attributed to the fact that PowerPoint employs multimedia. That enables students to form a mental image for knowledge. Thus, that enables students to save information in the long-term memory. Using PowerPoint doesn't create a classroom environment that is free from the feelings of anxiety and shyness which are associated with learning, because the relevant mean is 2.19 . The latter result is inconsistent with the result concluded by Al-Hashmi et al. (2010). The latter result may be attributed to the fact that the levels of such feelings in classroom are affected by the teachers' personality and emotional intelligence level. PowerPoint enables students to identify the main ideas and points of the lesson because the relevant mean is 4.69 . The latter result is consistent with the result concluded by Xingeng, and Jianxiang (2012).

PowerPoint program improves students' creative thinking capabilities, because the relevant mean is 4.91.The latter result is consistent with the result concluded by Neira et al. (2013) .This program improves my higher order thinking capabilities because the relevant mean is 4.82. The latter result is consistent with the result concluded by Al-Rasheedi (2013). The latter result may be attributed to the fact that PowerPoint enables students to see things that are difficult to bring to class and places that are difficult to visit. That participates in the development of students' imagination and thinking. PowerPoint is not considered as an effective teaching method in all the courses, because the relevant mean is 2.09 . That may be attributed to the fact that some skills can't be taught through using technology, such as: the skill of making sculptures.

\section{Conclusion}

After analyzing data, it was found that most of the primary school students in Saudi Arabia have excellent skills in using the PowerPoint program. PowerPoint program plays an effective role in teaching from the perspective of primary school students in Saudi Arabia. Primary school students' in Saudi Arabia have positive attitudes towards using this program in classroom. For instance, this program enriches students' knowledge, and increases 
their concentration, and academic achievement. It improves students' understanding of the material and problem solving skills. It enables students to retain information for a longer period of time. It enables students to identify the main ideas and points of the lesson and improves their creative thinking and higher order thinking capabilities. However, it doesn't increase students' interest in the course and the material. It doesn't participate in creating a classroom environment that is free from the feelings of anxiety and shyness which are associated with learning. It should be noted that the results of this study can't be generalized. That is because the study's results are limited to the study's sample, instrument and spatial and temporal limits. In the light of results of the present study, researchers should conduct studies about the effectiveness of using PowerPoint program in the courses of graduates and undergraduate programs. They should conduct studies about the impact of attitudes towards PowerPoint on the achievement of students at schools and universities.

\section{Recommendations}

The researcher recommends:

- Setting policies by the Saudi Ministry of Education for developing the IT infrastructure of Saudi schools.

- Holding training courses for teachers in Saudi Arabia about the way of using PowerPoint in classroom.

- Ensuring that all the classrooms in Saudi public schools are provided with computers and data show devices. That shall enable teachers in Saudi public schools to make PowerPoint presentations during classroom. It shall enable school students to develop their skills in using technology.

\section{References}

Abed Al-Rahman, A. (2016). The impact of using PowerPoint program on the academic achievement of third grade students (An empirical study in Dongola). Published MA thesis. Sudan. University of Dongola. Retrieved from http://repository.uofd.edu.sd/handle/123456789/133

Ahmad, S. (2016). Effectiveness of using PowerPoint program in teaching electricity at vocational training centers. Published MA thesis. Sudan. Sudan University of Science and technology. Retrieved from http://repository.sustech.edu/handle/123456789/14304

Ahmad, S. (2017). Using PowerPoint program in teaching biology course and its impact on academic achievement: Empirical study in Martyr Fathi Hemat Secondary School for Boys in Dongola. Published MA thesis. Sudan. University of Dongola. Retrieved from http://repository.uofd.edu.sd/handle/123456789/1605?show=full\&locale-attribute=ar

Al-Amery, A. (2020). Attitudes of the students at the institutes of fine arts in Iraq towards implementing active learning strategies in Arabic language courses and the associated challenges. Journal of Education and Practice, 11(13), 73-81.

Al-Hashmi, A., Soman, A., \& Al-Khateeb, M. (2010). Contemporary strategies for teaching Islamic education: From theoretical and empirical perspectives, Jordan. Alam Al-Thqafah Publication and Distribution House. Retrieved from http://academic.ju.edu.jo/A.Hashmi/Lists/PublishedBooks/DispForm.aspx?ID=14\&ContentTypeId=0x0100 4FC0EA508143BF40B65B28ECA293AD99

Ali, K., \& Sbeira, F. (2014). Attitudes of applied faculties students at Tishreen University towards the role of data show in motivating learning. Tishreen University Journal for Research and Scientific Studies: Art and Humanities Series, 36(3). Retrieved from http://91.144.21.197/index.php/humlitr/article/view/981/0

Al-Radi, A. (2016). The role of PowerPoint in raising academic achievement of first year secondary school students in engineering drawing subject. Published MA thesis. Sudan. Sudan University of Science and technology. Retrieved from http://search.shamaa.org/fullrecord?ID=245831

Al-Rasheedi, K. (2013). Attitudes of Kuwaiti basic education college students toward using Power Point technique by faculty stuff in the light of some variables. Published MA thesis. Amman. Jordan. The Middle East University. Retrieved from http://search.shamaa.org/FullRecord?ID=111806

Al-Shamat, M., Seyam, M., \& Tarboush, A. (2013). The effect of using program presentations (PowerPoint) on the achievement the tenth-grade students' in geography classes, and their attitudes towards it: an experimental study on secondary students in the province of Damascus. The Journal of Damascus University for Educational and Psychological Sciences, 29(1), 273-315. Retrieved from http://search.shamaa.org/FullRecord?ID=102007

Al-Shamsi, M. (2018). The impact of using PowerPoint program on 10th grade students' academic achievement 
in physical education in Al-Buraimi, Oman. Arab Journal of Sciences \& Research Publishing, 2(18), 51-66. Retrieved from https://www.ajsrp.com/h240418.html

Al-Shayeb, K., \& Ayesh, S. (2014). The attitudes of university students towards using PowerPoint program. The Proceedings of the Second National Conference on Computer and IT in Higher Education: 5-6 March, 2014. Retrieved from https://dspace.univ-ouargla.dz/jspui/handle/123456789/7802

Al-Taher, S. (2016). Effectiveness of using PowerPoint program in teaching drawing and painting to third classsecondary school Karary locality. Published MA thesis. Sudan. Sudan University of Science and technology. Retrieved from http://repository.sustech.edu/handle/123456789/15290

Ankolekar, V., Souza, A., Souza, A., \& Hosapatna, M. (2017). Effectiveness of Power Point presentations in teaching anatomy: A students' perspective. Advanced Science Letters, 23(3).

Fishbein, M., \& Ajzen, I. (1975). Belief, attitude, intention, and behavior: An introduction to theory and research. Reading, MA: Addison, Wesley.

Jalal, S. (2019). The effectiveness of using PowerPoint program in raising the academic achievement of the students suffering from physical impairments and learning difficulties in doing basic mathematical operations. The Journal of Palestine University for Studies and Research, 9(2). Retrieved from http://search.shamaa.org/FullRecord?ID=246536

Lari, F. (2014). The impact of PowerPoint presentation on students' learning and motivation in secondary schools. The Proceeding of the International Conference on Current Trends in ELT.

Liu, X., Yunrong, X., \& Jenny, P. (2016). Teachers' use of PowerPoint in kindergarten: An empirical investigation in China. Education and Information Technologies, 21(2), 425-441.

Mohsenzadeh, A., Marzban, A., \& Ebrahimi, S. (2014). Attitudes of EFL learners and instructors towards the application of Power Point presentation in Iranian classroom context. Journal of Applied Linguistics and Language Research, 1(2), 74-87.

Neira, E., Salinas, J., \& Crosetti, B. (2017). Emerging technologies (ETs) in education: A systematic review of the literature published between 2006 and 2016. International Journal of Emerging Technologies in Learning, 12(5), 128-149.

Papanastasiou, E. C., \& Zembylas, M. (2002). The effect of attitudes on science achievement: A Study Conducted among High School Pupils in Cyprus. International Review of Education, 48, 469-484. https://doi.org/10.1023/A:1021334424571

Salman, H. (2018). The effect of recent technology on university students' skills. The Journal of Educational and Psychological Research, 56, 196-216. Retrieved from http://search.shamaa.org/FullRecord?ID=127550

Shigli, K., Agrawal, N., Nair, C., Sajjan, S., Kakodkar, P., \& Hebbal, M. (2016). Use of PowerPoint presentation as a teaching tool for undergraduate students in the subject of gerodontology. The Journal of the Indian Prosthodontic Society, 16(2), 187-192.

Ul-Amin, S. (2016). ICT Integration in education: A smart concept of teaching and learning, India. Educreation Publishing.

Xingeng, D., \& Jianxiang, L. (2012). Advantages and disadvantages of PowerPoint in lectures to science students. International Journal Education and Management Engineering, 9, 61-65.

\section{Copyrights}

Copyright for this article is retained by the author(s), with first publication rights granted to the journal.

This is an open-access article distributed under the terms and conditions of the Creative Commons Attribution license (http://creativecommons.org/licenses/by/4.0/). 